\title{
O s neologismos ativos e passivos em Jules Séglas (1892)
}

Walker Douglas Pincerati

Des troubles du langage chez les aliénés de Jules Séglas, publicada em 1892, teve grande repercussão nos estudos psicopatológicos, principalmente no que diz respeito, como nomeou G. Berrios, à "Language of the insane". No que diz respeito às dislogias, a classificação neologismos ativos e neologismos passivos distingue com rigor os fenômenos observados no delírio daqueles observados em outras doenças. Essa distinção, contudo, não se fez sem destacar a importância da linguagem na relação médico-paciente. Palavras-chave: Jules Séglas, delírio, neologismo 
Louis Jules Ernest Séglas (1856-1939) foi, tanto para Berrios (1999) como para Lantéri-Laura (1983), um dos importantess autores do final do século XIX e início do XX que tiveram grande importância no estabelecimento da semiologia psiquiátrica.

A tradução que segue encontra sua justificativa nesse contexto. A história do termo 'neologismo' em psiquiatria não se resume apenas em uma incorreção terminológica praticada por essa disciplina, isto é, em uma simples importação mais ou menos abusiva desse conceito dos estudos da linguagem para utilizá-lo como designação de palavras insólitas dos alienados. Essa importação se deve à insuficiência conceitual e mesmo terminológica no alvorecer dessa disciplina como disciplina médica, na primeira metade do século XIX. O que se deve retirar da história desse termo na psiquiatria é, então, seu próprio uso pelos psiquiatras clássicos para designar determinados fenômenos de linguagem observados na clínica com os alienados. Ou seja, no contexto de desenvolvimento da semiologia da psiquiatria, a história do uso do termo 'neologismo' pode elucidar os esforços dos psiquiatras na construção de categorias clínicas.

Tais esforços podem ser notados nas classificações dos neologismos encontrados nas falas dos alienados. Nessas classificações encontramos também razões para desconfiar da identidade entre o que na psiquiatria se chama 'neologismo' e o que é um neologismo na linguística, mais precisamente, na lexicologia e lexicografia. Para essas últimas disciplinas, um neologismo é uma unidade lexical cuja forma significante ou cuja relação significado-significante não se tinha realizado no estágio imediatamente anterior da língua. Mais que isso, ele precisa ser interpretado pelo interlocutor para que possa ser chamado como tal. Ora, todo psiquiatra que se dedicou a esse tema colocou os "neologismos" dos alienados no nível da fala. É isso, a meu ver, que sustenta a afirmação de todos os psiquiatras de que esses neologismos consistem em erros.

É justamente a noção de erro, seja da percepção seja da “ideia”, que nos permite entrever uma polêmica em torno desse tema. De um lado, há aqueles que entendem os neologismos de todos os doentes apenas como erros de percepção ou de processamento. Tal abordagem faz uma aproxi- 
mação dos fenômenos de linguagem na afasia e nos delírios. Como se pode observar em Bobon (1952), esse tipo de abordagem não teve muitos adeptos, justamente pelo fato de que há lesão na afasia e, nos casos de delírio, não. A maioria dos psiquiatras entendeu que havia uma especificidade dos neologismos em conformidade com a doença.

Desde Snell (1852) os neologismos dos delirantes foram diferenciados dos encontrados nas demais doenças mentais. De um lado, há os neologismos resultantes de associações vertiginosas de representações, de uma pronunciação incompleta e/ou deformada das palavras, de memória falha ou de uma percepção incompleta das impressões sensoriais. Por outro, há os neologismos no delírio que estão notadamente ligados a ideias fixas e que são suscetíveis de um esclarecimento ulterior por parte do próprio doente. Tanzi (1889-1890) se filiará a essa concepção não só ao afirmar que na mania e nos delírios febris os neologismos são pobres e incolores, ao passo que nos paranoicos testemunham uma superprodutividade e uma funcionalidade, como também ao definir o neologismo do paranoico como um fato que testemunha o desenvolvimento e as proporções de uma ideia supersticiosa.

Propriamente, essa distinção, nas palavras de Maleval (1998), consiste em um esforço dos psiquiatras clássicos em distinguir os fenômenos próprios ao delírio das experiências meramente neuróticas de um imaginário desenfreado (p. 68). Nessas últimas, as ideias dominantes têm o caráter de suposição e são passageiras. Já o delírio dos psicóticos é marcado pela presença de ideias fixas impossíveis do ponto de vista lógico ou factual, ainda que comportem pontos verossímeis, nos quais o indivíduo deposita uma convicção inamovível pela argumentação racional. O delírio (do psicótico) é uma construção sistematizada. O onirismo do neurótico não é a logolatria do delirante, assevera Maleval (p.72).

No capítulo traduzido, em que aborda os estudos das modificações do conteúdo (e que leva esse nome) que ocorrem nas dislogias, isto é, nos distúrbios da linguagem falada resultantes de distúrbios intelectuais com integridade da função da linguagem, Séglas dedicou praticamente quase todo o capítulo aos neologismos.

Essa nitidez se traduz na famosa distinção dos neologismos em ativos, resultantes de um trabalho do delirante, e passivos, resultantes do automatismo psicológico. Segundo Séglas, o neologismo ativo revela uma sistematização do delírio, na medida em que se constitui como um símbolo de um fato supersticioso desenvolvendo-se na consciência do delirante. Isto é, constitui-se como símbolo de uma ideia fixa avançando. Por isso, para Séglas, ele é menos um sintoma patológico do que um índice de uma afecção crônica. Os neologismos passivos, pelo contrário, são relacionados a estados oniroides porque são passageiros e mo- 
mentâneos. Podem, então, ser encontrados tanto em estados incuráveis como benignos. Tudo isso abre a possibilidade de ler o ‘neologismo ativo' como correlato do 'neologismo esquizofrênico' de Freud (1915). O que quer dizer que o neologismo do psicótico é uma peça de grande importância na leitura do delírio como uma reconstrução.

Há alguns autores que atribuem a denominação 'neologismo ativo' e 'passivo’ a Charles Lefèvre (por exemplo, Biéder, Bubrovsky, Callens, 2002; Teulié, 1925), que publicou em 1891 sua tese de doutorado em psiquiatria Étude clinique des néologismes en médecine mentale (Paris: Publieur). Contudo, a maioria dos grandes psiquiatras e estudiosos da temática atribui essa denominação a Séglas. Dentre eles está Bobon (1952, p. 49), que curiosamente, à primeira vista, situa a origem dessa denominação em Séglas no ano de 1891. Não obstante, o próprio Séglas esclarece em nota que a trama de seu livro foi tema de uma série de conferências realizadas em 1891 no Hospital de la Salpêtrière. Lantéri-Laura (1994, p. 97) também atribui a origem dessa denominação a Séglas, e nem cita a tese de Léfevre. Em Maleval (1998) não encontramos afirmações nem de um nem de outro lado; a distinção neologismo ativo e neologismo passivo é atribuída, genericamente, à Escola francesa de psiquiatria. Esse autor cita os dois. Entretanto, esse último figura uma vez em nota de rodapé. São sempre as considerações feitas por Séglas que são trazidas à discussão. Por último, note-se que o próprio Séglas cita Léfevre, embora seja apenas para a construção geral da noção de neologismo passivo, e não relativo a doenças. Mais do que um problema para localizar a autoria da famosa denominação, o aspecto mais relevante está justamente nessa última informação: foi Séglas quem teve a importância de colocar esses termos em relação com as diferenças estruturais entre o delírio e os estados oniroides neuróticos, tais como observadas na clínica.

Cabe ressaltar que é o próprio Séglas quem dá os elementos para essa interpretação. Não é por acaso que em seu prefácio ele tenha destacado a importância da linguagem na relação médico-paciente como fundadora da possibilidade dessa relação. Segundo ele, é só por meio de uma prática que é a do interrogatório do alienado que se pode chegar a um exame psicológico do paciente. Sem esse interrogatório ou quando ele é mal dirigido chega-se a um mau diagnóstico e prognóstico. Deixo, porém, que o leitor retire das palavras de Séglas a densidade da dimensão, digamos, ética com que ele condiciona a escuta a ser emprestada pelo médico à fala do paciente:

A determinação do estado mental de um indivíduo compreende, além da apreciação das faculdades intelectuais nelas mesmas, a compreensão de seu nível, de seu funcionamento, de suas perversões mórbidas e, em particular, do delírio pro- 
priamente dito (concepções delirantes), dos distúrbios psicossensoriais (ilusões, alucinações), do sentimento, da vontade, a busca de atos patológicos do doente.

Para realizar esse exame psicológico é inteiramente necessário recorrer ao interrogatório do alienado. Não é possível entrar em comunicação com o doente senão por seu único procedimento que é a linguagem sob seus diferentes modos, e, tanto nos alienados como no homem são, será sempre pelo intermédio da linguagem, fala, escrita, gestos, que se exprimirão as modificações do pensamento e as diferentes emoções.

Ora, se não estamos familiarizados com a linguagem dos alienados, certamente os sintomas de nossos doentes podem passar despercebidos, serem mal interpretados; mesmo as indicações preciosas ao diagnóstico, ao prognóstico e ao tratamento podem ser negligenciadas. Além disso, quando refletimos que, salvo algumas variações concernentes ao meio social, à educação etc., os alienados de outrora como os de hoje e os de países de línguas diferentes exprimem todos, no fundo, seu delírio da mesma maneira, percebemos a importância que há em se familiarizar com sua linguagem.

Essas são as considerações que nos levaram a pensar que uma exposição dos diferentes distúrbios da linguagem, que podemos observar nos indivíduos afetados por doenças do espírito, poderia apresentar algum interesse (Séglas, 1892, p. 1-2; minha tradução).

\section{Referências}

Berrios, G. E. Falret, Séglas, Morselli, and Masselon, and the "Language of the Insane”: A conceptual history. Brain and Language, v. 9, n. 1, p. 56-75, 1999.

Bieder, J.; Bubrovsky, M.; Callens, H. Réflexions sur les néologismes. Annales Médico-Psychologiques, v. 160, p. 409-415, 2002.

Bовоn, J. Introduction historique a l'étude des néologismes et des glossolalies en psychopathologie. Liège: H. Vaillant-Carmanne, 1952.

Freud, S. (1915). O inconsciente. In: Escritos sobre a psicologia do inconsciente. Rio de Janeiro: Imago, 2006. v. II - 1910-192.

LANTÉRI-LAURA, G. (1994). Recherches psychiatriques: sur le langage. Chilly-Mazarin: Editions Sciences en Situation, 1994. v. I.

. (1983). La sémiologie psychiatrique: son évolution et son état en 1982.

L’Évolution Psychiatrique, v. 72, n. 4, p. 747-770, 2007.

Maleval, J-C. Lógica del delírio. Barcelona: Ediciones del Serbal, 1998.

SÉGlas, J. Des troubles du langage chez les aliénés. Paris: J. Rueff et $C^{\mathrm{ie}}$ Editeurs, 1892. 
SnELl, L. D. Ueber die veränderte Sprechweise und die Bildung neuer Worte und Ausdrücke in Wahnsinn. Allgemeine Zeitschrift für Psychiatrie und psychiatrisch gerichtliche Medizin, Berlin, v. 9, p. 11, 1852.

TANZI, E. I neologismi degli alienati in rapporto col delirio cronico. Rivista Sperimentale di Freniatria e di Medicina Legale delle Alienazioni Mentali, v. 15, p. 352-393, 1889-1890.

Teulié, G. Les rapports des langages néologiques et des idées délirantes en médecine mentale. Paris: Éd. Auguste Picard; Leipzig: Éd. Alfred Lorentz, 1925.

Resumo

(Los neologismos activos e pasivos en Jules Séglas [1892])

Des troubles du langage chez les aliénés de Jules Séglas, publicada en 1892, tuvo gran repercusión en los estudios psicopatológicos, principalmente en lo que respecta, como lo denominó Berrios, a la "Language of the insane". Respecto a las dislogias, la clasificación neologismos activos y neologismos pasivos distingue con rigor los fenómenos observados en el delirio de aquellos observados en otras molestias. Ésta distinción, sin embargo, no se hizo sin poner en destaque en la importancia del lenguaje en la relación médico-paciente.

Palabras claves: Jules Séglas, delirio, neologismo

(Les néologismes actifs et passifs chez Jules Séglas[1892])

Des troubles du langage chez les aliénés, par Jules Séglas, publié en 1892, a eu une grande répercussion sur les études psychopathologiques, surtout en ce qui concerne le «langage de l'insensé» («language of the insane»), d'après G. Berrios. À l'égard des dyslogies, la classification entre néologismes actifs et passifs différencie rigoureusement les phénomènes observés dans le délire de ceux observés dans les autres maladies. Cependant, cette distinction n'a pas été obtenue sans mettre en relief l'importance du langage dans le rapport médecin-patient.

Mots clés: Jules Séglas, délire, néologisme

(The active and passive neologisms in Jules Séglas [1892])

Jules Séglas's Des troubles du langage chez les aliénés, published in 1892, had wide repercussions in the area of psychopathological studies, especially in regard to what G. Berrios calls the "Language of the Insane." Concerning dyslogias, the classification of active and of passive neologisms clearly distinguishes the phenomena found in delusions from those seen in other disorders. This distinction, however, could 
not be made without calling attention to the importance of language in the relationship between doctor and patient.

Key words: Jules Séglas, delusion, neologism

Citação/Citation: Pinceratı, W.D. Os neologismos ativos e passivos em Jules Séglas (1892). Revista Latinoamericana de Psicopatologia Fundamental, São Paulo, v. 12, n. 3, p. 564-570, set. 2009.

Editor do artigo/Editor: Prof. Dr. Mário Eduardo Costa Pereira.

Recebido/Received: 30.7.2009 / 7.30.2009 Aceito/Accepted: 3.8.2009 / 8.3.2009

Copyright: @ 2009 Associação Universitária de Pesquisa em Psicopatologia Fundamental/ University Association for Research in Fundamental Psychopathology. Este é um artigo de livre acesso, que permite uso irrestrito, distribuição e reprodução em qualquer meio, desde que $\mathrm{o}$ autor e a fonte sejam citados/This is an open-access article, which permits unrestricted use, distribution, and reproduction in any medium, provided the original author and source are credited.

Financiamento/Funding: Pesquisa financiada pelo Conselho Nacional de Desenvolvimento Científico e Tecnológico - CNPq/Research funded by the National Counsel of Technological and Scientific Development.

Conflito de interesses: $\mathrm{O}$ autor declara que não há conflito de interesses/The author declares that has no conflict of interest.

\section{Walker Douglas Pincerati}

Doutorando em Linguística na Universidade Estadual de Campinas - Unicamp (Campinas, SP, Brasil), com bolsa do Conselho Nacional de Desenvolvimento Científico e Tecnológico - CNPq (Brasília, DF, Brasil); mestre em Linguística pela Universidade Estadual de Campinas - Unicamp, com a dissertação "O estatuto da palavra que tem efeito neológico na construção delirante”, com bolsa da Fundação de Amparo à Pesquisa do Estado de São Paulo Fapesp (São Paulo, SP, Brasil), e bacharel em Linguística pela mesma Universidade.

Rua Bernardino de Campos, 1055/72 - Centro

13010-151 Campinas, SP, Brasil

e-mail: pincerati@gmail.com 